\section{Tumorigênese Molecular Tiroideana: Implicações Para a Prática Médica}

\section{RESUMO}

Esta revisão apresenta aspectos de utilidade prática da tumorigênese tiroideana. O mais importante é a possibilidade de se fazer o diagnóstico genético precoce dos indivíduos portadores de mutações do gene RET em famílias com carcinoma medular de tiróide e neoplasia endócrina múltipla tipo 2. Além disso, discutem-se dados relativos à patogênese molecular dos carcinomas diferenciados da tiróide, relacionados aos rearranjos entre RET e outros genes no caso do carcinoma papilifero (RET/PTC) e entre PAX-8 e PPARgl no carcinoma folicular da tiróide. A seguir, analisam-se as mutações que causam ganho de função no receptor de TSH, causadoras dos nódulos autônomos. Finalmente, apresenta-se o emprego do RNA mensageiro da tiroglobulina no seguimento de pacientes com câncer de tiróide. (Arq Bras Endocrinol Metab 2002;46/4:381-390)

Descritores: Tumorigênese tiroideana; Gene RET; Carcinoma de tiróide; Neoplasia endócrina múltipla; TSH; Tiroglobulina

\begin{abstract}
Molecular Thyroid Tumorigenesis: Implications for The Clinical Practice. In this review we present practical aspects of thyroid molecular tumorigenesis. The most important issue is the molecular diagnosis of affected patients with RET mutations in families with medullary thyroid carcinoma and multiple endocrine neoplasia type 2. In addition, we discuss the molecular pathologenesis of differentiated thyroid carcinoma, like the data on RET/PTC rearrangements in papillary carcinoma and PAX8PPARg 1 rearrangement in follicular carcinoma. Subsequently, we present gain of function mutations in thyroid nodules and finally we conclude discussing the use of messenger RNA of thyroglobulin in the followup of patients with differentiated thyroid cancer. (Arq Bras Endocrinol Metab 2002;46/4:381-390)
\end{abstract}

Keywords: Thyroid tumorigenesis; RET gene; Thyroid carcinoma; Multiple endocrine neoplasia; TSH; Thyroglobulin

O NÓDUlOS DE TIRÓIDE SÃO MUITO prevalentes na população e o câncer de tiróide é a neoplasia endócrina mais comum. Assim, é natural que diversos grupos clínicos e de pesquisa, nestes últimos anos, tenham dirigido seus esforços para o entendimento da patogênese molecular da proliferação anormal do tecido tiroideano, com o objetivo de aperfeiçoar o diagnóstico das várias doenças envolvidas e contribuir para o seu tratamento. Desta forma, vários artigos de revisão analisaram este tema, inclusive nos "Arquivos" (1-3). Apesar de todo esse esforço de pesquisa, entretanto, ainda são poucas as contribuições que já estão sendo utilizadas na clínica. O foco desta apresentação é examinar o impacto desses novos conhecimentos na prática médica diária. revisão

Rui M.B. Maciel

\author{
Laboratório de Endocrinologia \\ Molecular, Disciplina de \\ Endocrinologia, Departamento de \\ Medicina, Escola Paulista de \\ Medicina, Universidade Federal de \\ São Paulo; e Fleury - Centro de \\ Medicina Diagnóstica, \\ São Paulo, SP.
}


Entre essas contribuições, a mais importante é, sem dúvida, a possibilidade de diagnosticar os indivíduos portadores de mutações do gene RET em famílias com carcinoma medular de tiróide (MTC, do inglês medullary thyroid carcinoma) e conseguir a cura da doença, antes mesmo de sua apresentação clínica. Além desse aspecto, discutiremos também os dados relativos à patogênese molecular dos carcinomas diferenciados da tiróide, relacionados aos rearranjos entre o RET e outros genes no caso do carcinoma papilífero e entre PAX-8 e PPAR $\gamma 1$ no caso do carcinoma folicular da tiróide. A seguir, analisaremos as mutações que causam ganho de função no receptor de TSH, causadoras dos nódulos autônomos. Finalmente, apresentaremos o emprego de alguns marcadores moleculares que estão sendo propostos para o diagnóstico e seguimento do câncer da tiróide.

\section{Mutações do Gene RET na Neoplasia Endócrina Múltipla Tipo 2 e no Carcinoma Medular de Tiróide Hereditário}

Mutações germinativas do protooncogene RET causam predisposição para todas as formas de carcinoma medular da tiróide familiar (FMTC, do inglês familial medullary thyroid carcinoma), seja quando estas fazem parte da neoplasia endócrina múltipla tipo 2 (MEN 2, do inglês multiple endocrine neoplasia, type 2), seja quando se apresentam como manifestação isolada.

\section{Formas hereditárias de MTC}

A MEN2 é uma síndrome neoplásica rara caracterizada pela transmissão autossômica dominante com penetrância e expressividade variáveis entre as cerca de 1000 famílias afetadas descritas até hoje (1-8). Diversas variantes da doença têm sido relatadas, todas apresentando penetrância elevada para MTC (tabela l). Na verdade, casos de MEN2 correspondem a apenas cerca de $25-30 \%$ dos pacientes diagnosticados de MTC, a grande maioria sendo ainda considerada esporádica; por sua vez, os casos de MEN2A correspondem a 75\% de todas as MEN. Entre os adultos afetados com MEN2A, cerca de 90\% deles apresentam MTC, 50\% feocromocitomas e 20-30\% tumores da paratiróide. As formas variantes de MEN2A incluem o MTC familiar, o MEN2A com líquen amilóide cutâneo e o FMTC com doença de Hirschprung (tabela 1 ).

O MTC é um tumor das células C ou para-foliculares da tiróide produtoras de calcitonina, que representa cerca de $10 \%$ de todos os tumores da tiróide $(6,7)$. Habitualmente, antes da transformação em tumor ocorre a hiperplasia multifocal das células C, lesão precursora do MTC, cuja progressão é variável e pode levar muitos anos. O MTC pode apresentar metástases locais para os linfonodos das cadeias centrais, laterais, cervicais e mediastinais, além de metástases à distância, especialmente para o pulmão, fígado e ossos. O produto principal secretado pelo MTC é a calcitonina, que funciona como excelente marcador tumoral para a persistência ou recorrência da moléstia. Os valores de calcitonina são habitualmente elevados nos casos de MTC; além disso, estímulos com pentagastrina ou cálcio provocam a elevação da calcitonina em indivíduos com MTC. A prevenção ou cura do MTC é a cirurgia, cuja técnica consiste na tiroidectomia total associada ao esvaziamento da cadeia central (4-8).

Como mencionado, mais de $70-75 \%$ dos casos de MTC é esporádico, mas cerca de $25-30 \%$ dos casos são, habitualmente, a primeira manifestação neoplásica de famílias com MEN2A, tendo em vista sua elevada penetrância e seu aparecimento precoce. Desta forma, é possível que pacientes provenientes de famílias com MEN2A constituídas por um pequeno número de componentes, manifestem inicialmente apenas o MTC; assim, seriam diagnosticados apenas como FMTC e não como MEN2A, o que ocasionaria a falta de uma procura ativa para o diagnóstico de feocro-

Tabela 1. MEN2 e suas síndromes ou variantes clínicas.

\begin{tabular}{ll}
\hline Síndrome & Achados característicos \\
\hline MEN2A & MTC (90\%) \\
& Feocromocitoma (50\%) \\
FMTC & Hiperparatiroidismo (25\%) \\
MEN2A com líquen amilóide cutâneo & MTC \\
MEN2A com doença de Hirschprung & MEN2A e lesão pruriginosa nas costas \\
MEN2B & MEN2A ou FMTC com doença de Hirschprung \\
& MTC \\
& Feocromocitoma \\
& Ganglioneuromatose intestinal e mucosa \\
& Hábitus marfanóide \\
\hline
\end{tabular}


mocitoma, o que poderia causar o risco do indivíduo afetado ser surpreendido por uma crise hipertensiva. Tendo em vista estas considerações, tem-se sugerido que para a categorização de uma família como portadora de FMTC, os seguintes critérios deverão ser preenchidos: mais de 10 portadores na família, múltiplos indivíduos afetados com idade acima de 50 anos e história médica completa; desta forma, esse critério conservador transfere deliberadamente várias pequenas famílias com FMTC para a categoria de MEN2A, para que se evite o risco de se deixar de diagnosticar um caso de feocromocitoma $(7,8)$.

A outra forma de MEN2, MEN2B, caracterizase por MTC de comportamento muito agressivo e feocromocitoma, associados a neuromas na mucosa oral e no trato gastrintestinal, além de fenótipo semelhante à síndrome de Marfan, como braços longos e relação tronco-membros alterada (4-8).

FMTC são aquelas famílias nas quais o MTC é transmitido como traço autossômico dominante sem as outras manifestações de MEN2 (tabela 1).

\section{Estrutura e função do RET}

O gene RET (rearranged during transfection) codifica, no homem, um receptor transmembranoso da família das tirosino-quinases ( $\mathrm{TK}$, do inglês tyrosinekinase) para uma família de ligantes, da qual o paradigma é o fator de crescimento neurotrófico derivado de células da glia (GDNF, glial cell-derived neurotropic growth factor) $(1,2,4,10)$. O gene RET está envolvido na regulação, sobrevivência, diferenciação e migração das células derivadas da crista neural; está localizado no cromossomo $10 \mathrm{ql} 1.2$, contém 21 exons que ocupam mais de $60 \mathrm{~kb}$ do DNA genômico e é transcrito em pelo menos 10 isoformas alternativas (2-4).

A proteína RET é dividida em 3 regiões, um domínio extracelular que contém o peptídeo-sinal, um sítio com homologia à caderina e outra região rica em cisteína, um domínio transmembranoso e um domínio intra-membranoso, que apresenta a TK (figura 1). Como mencionado, o RET é o receptor dos fatores de crescimento pertencentes à família dos fatores neurotróficos GDNF, semelhantes a TGF $\beta$, que apresentam influências tróficas em diversas populações de neurônios e incluem, além do GDNF, a neurturina (NTN), a persefina (PSP) e a artemina $(1,2)$. A resposta fisiológica a esses agentes requer a interação com um complexo multimérico composto pelo RET e por co-receptores de alta-afinidade para o glicosil-fosfatidil-inositol (GPI). Já se isolaram 4 desses co-receptores ligados a GPI, que se denominam GFR $\alpha 1,2,3$ e 4, e ligam-se de modo preferencial a GDNF, NTN,

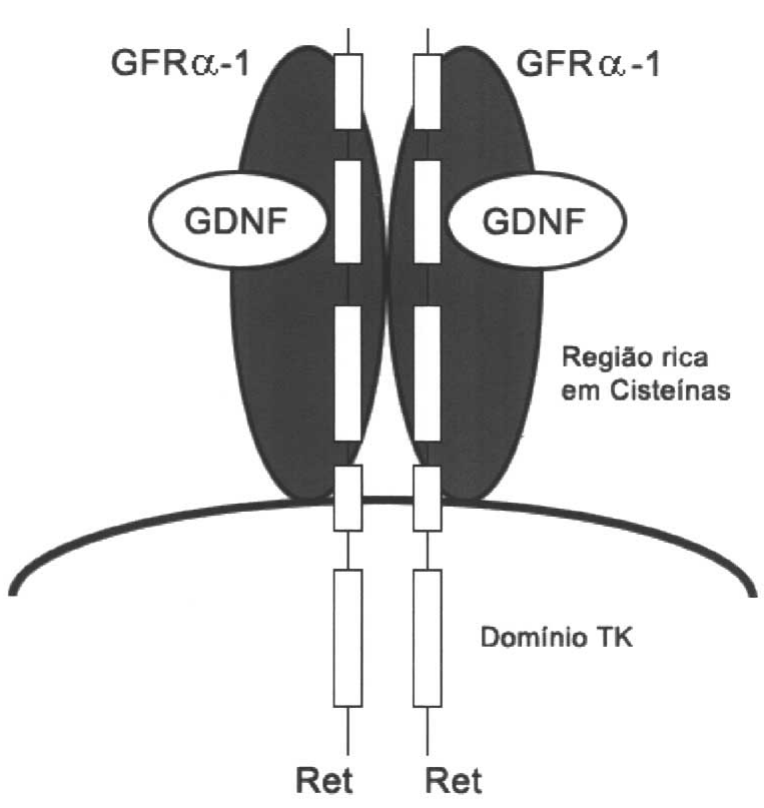

Figura 1. A proteína RET é um receptor caracterizado por 3 regiões principais: um domínio extra-celular onde se dá a ligação com o ligante, no caso o GDNF (fator de crescimento neurotrófico derivado de células da glia); um domínio transmembranoso; e uma porção intracelular contendo o domínio tirosina-quinase (TK). A porção extracelular complexa-se com co-receptores de alta-afinidade para o glicosil-fosfatidil-inosotol (GPI), conhecidos como GFR $\alpha-1$, para formar um complexo receptor multimérico com o qual os ligantes específicos, no caso o GDNF interagem (modificado a partir da referência 5).

artemina e PSP, respectivamente. A seguir, os complexos ligante-receptor interagem com o RET e induzem a dimerização, com a conseqüente ativação da quinase, auto-fosforilação e iniciação da transdução do sinal, que promove, como mencionado, a sobrevivência neuronal, além da diferenciação e da migração das células da crista neural (figura 1) $(1,2)$.

\section{Mecanismos da Ativação da RET-TK}

As diferentes formas clínicas de MEN2 estão associadas a mutações distintas do RET que causam alteração de apenas um aminoácido. Todas essas mutações de ponto provocam um efeito de "ganho de função" que causam, por sua vez, uma ativação descontrolada da atividade TK do receptor. O mecanismo molecular dessas alterações é uma dimerização constitutiva que afeta as cisteínas extracelulares; apesar da estrutura tridimensional do domínio extracelular do RET ainda ser desconhecida, estas cisteínas formam, provavelmente, pontes dissulfeto no receptor mutado que resultam numa cisteína não-pareada que forma uma ponte intermolecular ativadora (2) (figura 2). A explicação dos diferentes fenótipos encontrados na prática 


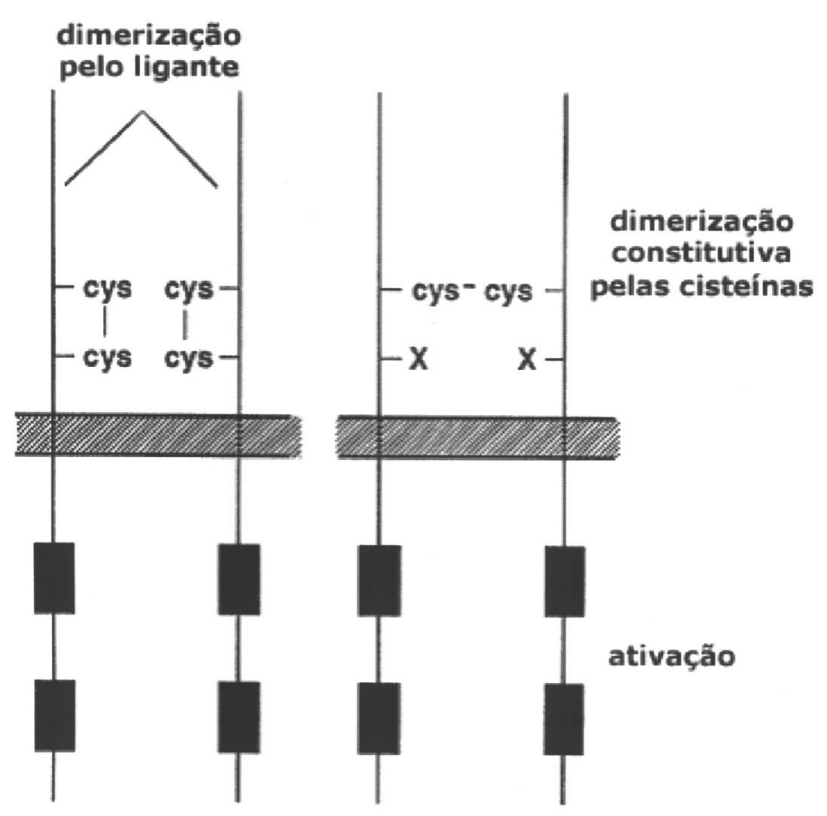

Figura 2. Ativação constitutiva do RET como resultado da mutação de uma cisteína no domínio extracelular. Normalmente (figura da esquerda), quando ocorre a ligação com o GDNF ou outro ligante, há a dimerização do receptor, o que ativa a tirosino-quinase (TK). Quando ocorre a mutação no RET (figura da direita) as cisteínas formam pontes di-sulfeto ativadoras no receptor mutado induzindo uma dimerização constitutiva (modificado a partir da referência 4).

clínica é dada pelas intensidades variadas de indução da dimerização observadas nas diversas mutações. Assim, mutações de RET associadas a FMTC apresentam uma dimerização menor e isto explica porque suas atividades quinase e oncogênicas são menores que as apresentadas pelos mutantes de MEN2A.

No caso de MEN2B as mutações causam uma ativação constitutiva do potencial transformador do $R E T$, pois além das alterações quantitativas da atividade basal da atividade quinase, a mutação mais freqüente (Met918Thr) afeta a qualidade dos sinais intracelulares. Um dos seus efeitos é mudar a especificidade do substrato da TK de uma quinase típica de receptor (RTK) (sempre com metionina na posição 918) para uma quinase típica do citoplasma (com a treonina na posição 918), o que causa ativação sem a necessidade de dimerização, pois esse resíduo localiza-se na região da ligação do substrato. Desta forma, o mecanismo molecular pelo qual a mutação Met918Thr altera a função de RET é, provavelmente, múltiplo; por um lado, a mutação causa uma ativação independente do ligante sem promover a dimerização constitutiva das moléculas de RET; por outro lado, o Met918Thr modifica a especificidade do substrato RET, o que causa a modifi- cação da autofosforilação assim como o padrão intracelular de fosforilação das proteínas. A quinase do MEN2B pode ser ainda mais ativada pelo ligante e por causa disso é que a estimulação é mais forte que a causada pelas mutações $\operatorname{MEN} 2 \mathrm{~A}(2,4,5)$.

\section{Espectro de Mutações do RET no MTC Hereditário}

$\mathrm{O}$ diagnóstico de que um indivíduo é portador de mutações no RET é um dos poucos exemplos na prática médica em que a realização de um teste genético pode definir uma intervenção clínica efetiva (tabela 2 e figura 3). Este assunto é, no entanto, ainda objeto de controvérsias, pois a cada dia descrevem-se novas famílias com mutações novas ou já conhecidas e ganha-se mais experiência com o seguimento dos pacientes, o que provoca mudanças nas freqüências específicas das mutações e modificações na conduta médica. Utilizaremos neste texto os dados provenientes do último consenso sobre MEN2, com o acréscimo dos dados nacionais sobre a doença $(8,9,11-17)$.

As mutações que causam MEN2A afetam, especialmente, o domínio extracelular, envolvendo a conversão dos resíduos cisteína para outro tipo de aminoácido no códon 634 (exon 11) ou nos códons 609, 611, 618, 620 (exon 10); essas mutações correspondem a mais de 95\% das mutações descritas para MEN2A, sendo que só a mutação no códon 634 representa $80 \%$ dos casos. Por outro lado, metade das famílias com FMTC apresentam mutações no exon 10, nos códons 618 e 620, aparecendo num número limitado de famílias mutações no exon 11 (códons 630, 631), enquanto que a outra metade inclui mutações nos códons 768, 790, 791 (exon 13), 804, 844 (exon 14) e 891 (exon 15), no domínio intracelular. Desta forma, mais de $95 \%$ das famílias descritas com MEN2A e FMTC têm a mutação num desses códons (tabela 2, figura 3 ).

Como dissemos, a descrição de novas famílias e a disponibilidade do estudo dessas mutações em diversos países com composição genética e ambiental diferente vai modificar, provavelmente, esses números. Nós, por exemplo, descrevemos recentemente uma família muito numerosa com uma nova mutação no exon 8 (14), o que ocasionou uma modificação substancial na casuística brasileira. Até então, tinham sido descritos estudos moleculares de 26 famílias brasileiras portadoras de MEN2A ou FMTC, sendo 11 mencionadas pelo grupo da Faculdade de Medicina da

\begin{tabular}{ll} 
Tabela 2. Correlação entre genótipo e fenótipo no MTC. \\
\hline MEN2A: & $634>618>620>611>609>790>V 804 L$ \\
FMTC: & $609>611>618>620>768>V 804 L>891$ \\
MEN2B: & $918>883>922$ \\
\hline
\end{tabular}




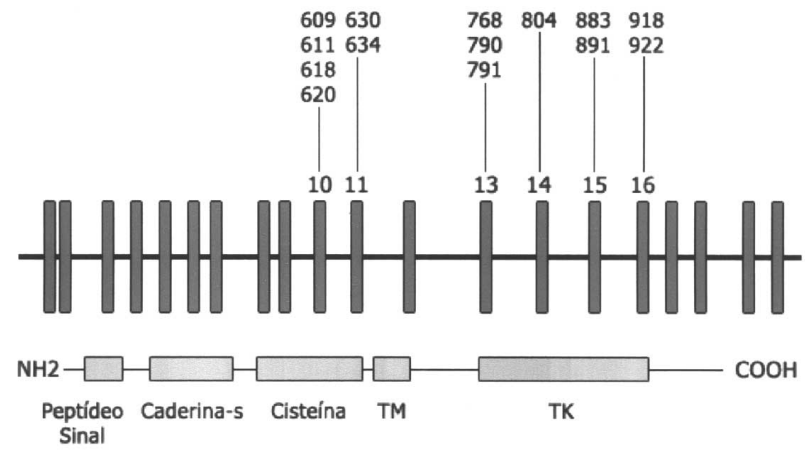

Figura 3. Mutações do RET em MEN2 e FMTC. No desenho inferior vemos um esquema dos domínios do RET da porção $\mathrm{NH} 2$ à esquerda até a porção $\mathrm{COOH}$ à direita; no desenho central observamos os exons extracelulares, ricos em cisteína $(10$ e 11) e os exons intracelulares, no domínio TK $(13,14,15$ e 16) onde ocorrem as mutações mais frequentes; no desenho superior notamos os códons mais frquentemente mutados (modificado a partir da referência 16).

Universidade Federal do Rio Grande do Sul (11), 12 pelo grupo da Faculdade de Medicina da Universidade de São Paulo (12) e 3 pelo grupo da Faculdade de Medicina de Ribeirão Preto - USP (13), que apresentaram, como no resto do mundo, grande predomínio de mutações no códon 634 (exon 11) (61,5\%, 16/26 famílias); a seguir, houve 4 famílias (15\%) com mutações no códon 804 (exon 14), 3 (11,5\%) no códon 618 (exon 10), duas (8\%) no códon 620 (exon10) e uma família (4\%) no códon 611 (exon 10).

Diferente dessa grande heterogeneidade que ocorre com famílias de MEN2A e FMTC, uma única mutação que converte metionina em treonina no códon 918 (exon 16) é responsável por 95\% dos casos de MEN2B (8). Nos 3 casos brasileiros onde houve estudo molecular de MEN2B a mutação foi no códon 918 (Met918Thr, exon 16) $(11,12,15)$.

Existe correlação entre o genótipo e o fenótipo (tabela 2); assim, o risco de feocromocitoma é de 50\% nos indivíduos com mutação no códon 634 e de $10 \%$ naqueles com mutação no exon 10 . Da mesma forma, hiperparatiroidismo ou líquen amilóide cutâneo só aparecem nos pacientes com MEN2A com a mutação 634. Por outro lado, aqueles indivíduos com mutações nos exons 13 ou 14 evidenciam doença menos agressiva ou que aparece mais tardiamente.

\section{Rastreamento dos indivíduos que apresentam risco para carcinoma medular de tiróide hereditário}

Nas séries mais antigas de MEN2A ou FMTC a mortalidade por MTC era ao redor de $20 \%$, pois o tratamento iniciava-se apenas após a descoberta do nódulo na tiróide
$(4,8,9,17)$. A seguir, como se sabe que $50 \%$ dos parentes de primeiro grau do paciente afetado irão desenvolver a doença, introduziram-se as dosagens sensíveis de calcitonina e os testes de estímulo com pentagastrina ou cálcio, realizadas anualmente, com a indicação de tiroidectomia total naqueles pacientes com o teste alterado; esta abordagem diagnóstica causou a diminuição da mortalidade por MCT para $5 \%$ dos casos $(4,8)$. Além disso, a descoberta dos casos de MEN2A obtida pelo rastreamento com a calcitonina contribuiu para o diagnóstico precoce de feocromocitoma nessa síndrome, uma vez que esses indivíduos foram investigados de maneira preventiva para feocromocitoma, o que também auxiliou para a queda de mortalidade de MEN2. A interpretação dos testes, porém, é problemática, pois além de caros, muitas vezes obtêm-se resultados com valores perto do limite indicativo de uma possível neoplasia e a decisão de indicar ou não a tiroidectomia é difícil de ser tomada, especialmente em crianças $(4,8)$.

Desta forma, tem-se recomendado recentemente a indicação da tiroidectomia baseada no diagnóstico genético, pois o códon mutado do RET correlaciona-se com a variante do MEN2, incluindo-se a agressividade do MTC. Assim, o códon mutado e os achados clínicos da família devem ser considerados na planificação da conduta para os pacientes portadores de mutação. Na última reunião de consenso estratificou-se o risco e recomendou-se uma série de decisões de acordo com as mutações conhecidas $(8,9)$.

Assim, crianças com MEN2B e/ou mutações no RET dos códons 883,918 ou 922 são classificadas como nível 3 ou de altíssimo risco de forma agressiva de MTC e devem ser submetidas à tiroidectomia total com dissecção central dentro dos primeiros 6 meses de vida, preferencialmente dentro do primeiro mês, pois o achado de MTC microscópico no primeiro ano de vida é comum; se metástases forem identificadas à cirurgia, esta deve ser mais extensa $(8,9,16,17)$.

As crianças que apresentam mutações nos códons $611,618,620$ e 634 são classificadas como nível 2 ou de risco elevado para MTC e devem ter sua tiroidectomia total com remoção da cápsula posterior realizada antes da idade de 5 anos (16).

Crianças com mutações no RET nos códons $609,768,790,791,804$ e 891 são classificadas como nível 1 ou de risco menos elevado para MCT; devem, também, ser submetidas à tiroidectomia total por ocasião do primeiro teste da pentagastrina alterado (16).

\section{Aconselhamento Genético Pré-teste}

É recomendável a realização de uma sessão de aconselhamento genético para os familiares de MEN2A e 
FMTC antes da autorização da colheita de sangue. Assim, adultos, crianças e pais deverão saber algo sobre transmissão genética e a probabilidade de herança genética numa doença autossômica dominante, sobre os riscos e os benefícios do teste, que incluem o potencial para discriminação, erros e futuras tecnologias. Além disso, deverão ser explicados dados sobre as possibilidades de tratamento e a necessidade de seguimento prolongado para os afetados.

\section{Rearranjos do Gene RET no Carcinoma Papilífero de Tiróide}

Diferentemente das células $C$, que são derivadas da crista neural, o gene RET não é expresso normalmente nas células foliculares da tiróide. Porém, a expressão aberrante de várias formas de RET pode ocorrer exclusivamente no carcinoma papilífero da tiróide, fato resultante de rearranjos cromossômicos entre fragmentos carboxi-terminais do RET e promotores de outros genes não-relacionados, o que causa uma fusão destes novos parceiros que gera novos oncogenes quiméricos, denominados RET/PTC (do inglês, papillary thyroid carcinoma, PTC) $(2,3)$.

Já se descreveram diversos tipos de RET/PTC, sempre decorrentes da fusão de seu domínio TK intracelular com fragmentos 5' de diversos genes (figura 4). Assim, o primeiro desses rearranjos a ser des- crito, o RET/PTCl, é uma quimera resultante da fusão da região tirosina-quinase (TK) do proto-oncogene RET com a região terminal 5 ' de outro gene, chamado H4/Diosi70, ambos localizados no cromossomo 10. Tal união é devida a um rearranjo intracromossômico do tipo inversão paracêntrica, localizado no braço longo do cromossomo 10, inv (10q11.210q21): assim, uma seqüência de 354 pares de bases, que faz parte do gene $\mathrm{H} 4$, substitui a região truncada do proto-oncogene RET. Por sua vez, o RET/PTC2 é formado pela translocação recíproca entre os cromossomos 10 e 17, o que resulta numa justaposição do domínio TK do RET com uma porção da subunidade regulatória $\mathrm{Rl} \alpha$ da PKA dependente de cAMP. O RET/PTC3, por outro lado, é o resultado do rearranjo intra-cromossômico formado pela fusão dos genes RFG/ELEl.

As recombinações mais freqüentemente encontradas até agora pela literatura são RET/PTCl e RET/PTC3, mas várias outras combinações novas têm sido descritas, especialmente em casos de carcinoma papilífero de crianças expostas à radiação em Chernobyl $(2,3,17)$.

A característica comum aos genes que se fundem ao RET é a capacidade de se expressarem de forma onipresente, em todos os tecidos, o que permite o aparecimento da forma alterada do gene RET nas

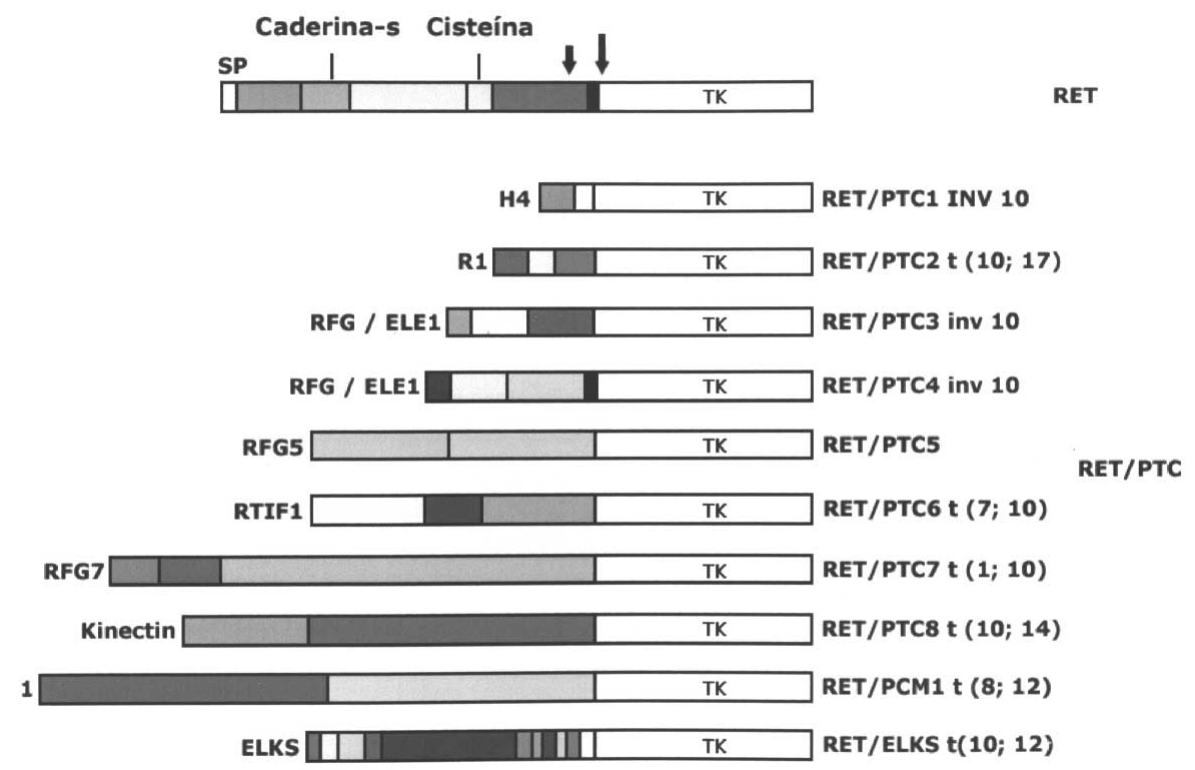

Figura 4. Tipos de oncogenes RET/PTCl a 10 encontrados em carcinomas papilíferos. $O$ esquema apresenta o desenho do RET normal na primeira linha e, a seguir, os 10 tipos de RET/PTC descritos até agora; todos são quimeras gerados pela fusão do domínio TK do RET com genes diferentes heterólogos. As flexas indicam os pontos de quebra. SP= peptídeosinal (modificado a partir da referência 2). 
células foliculares, local onde este gene não se expressa normalmente. Assim, todos estes novos rearranjos guardam a mesma conformação, ou seja, perda dos domínios extra-celular e transmembranoso nos fragmentos truncados de RET e localização da proteína aberrante dentro do citoplasma. Da mesma forma, todos os rearranjos RET/PTC são genes quiméricos constitutivamente ativados que apresentam sinalização dependente da dimerização do domínio derivado do fragmento $\mathrm{N}$-terminal doado pelos diversos genes parceiros nas correspondentes fusões $(2,3)$. A análise e a caracterização dos pontos de quebra gerados na formação desses genes quiméricos, em termos de DNA genômico, têm demonstrado que a fusão com os diferentes genes ocorre sempre no mesmo nucleotídeo da seqüência de codificação do proto-oncogene RET. Assim, em todos os tumores analisados, os pontos de quebra ocorrem dentro do intron que precede o primeiro exon do domínio tirosino-quinase do protooncogene RET, o exon 12. Desta maneira, os rearranjos envolvendo o RET/PTCl podem ser detectados por Southern blot ou, preferencialmente, por Reverse transcription polymerase chain reaction (RT-PCR) nos DNAs extraídos dos tumores dos pacientes $(17,18)$.

A freqüência da ativação do proto-oncogene RET/PTC em pacientes com carcinoma papilífero da tiróide varia entre as diferentes áreas geográficas. De fato, enquanto $33 \%$ dos pacientes italianos apresentam ativação do proto-oncogene $R E T / \mathrm{PTC}$, a freqüência foi muito menor entre os japoneses, oscilando de 3 a 9\%. Mais recentemente diversos laboratórios têm relatado até $60 \%$ de ativação de RET/PTC em amostras de câncer papilífero de tiróide provenientes de crianças expostas à radiação em Chernobyl ou à radiação externa para o tratamento de doenças benignas da cabeça e pescoço (3). Além da exposição à radiação, outro fator que pode estar relacionado à presença de rearranjos tipo $R E T / P T C$ é a idade de aparecimento do tumor, pois a porcentagem de casos positivos para rearranjos de RET/PTC é muito maior nos indivíduos jovens. Estes resultados sugerem que diferenças genéticas, de idade $\mathrm{e} /$ ou fatores ambientais podem alterar a freqüência de rearranjo deste gene; além disso, outros genes, tais como os genes supressores de tumores ( $553, \mathrm{Rb})$, também podem exercer um papel relevante no desenvolvimento de carcinoma papilífero da tiróide $(2,3,17)$. Em São Paulo observamos, em 12 pacientes com carcinoma papilífero, a presença de rearranjos RET/PTC em 3 $(25 \%)$, todos com idades inferiores a 39 anos (18).

Vários trabalhos evidenciam que os rearranjos $R E T / P T C$ estão relacionados à patogênese do carcinoma papilífero. Assim, uma elevada proporção de focos ocultos de carcinomas papilíferos, considerados os precursores dessa doença, apresenta imuno-reatividade para RET ou o RNa mensageiro (mRNA) de RET/PTC por RT-PCR. Além disso, uma superexpressão de RET/PTCl ou RET/PTC3 em células tiroideanas de camundongos transgênicos provocam tumores com histologia típica de carcinoma papilífero. Finalmente a irradiação de tecido fetal humano in vitro induz os rearranjos RET/PTC de uma maneira dosedependente $(2,3)$.

A possível explicação molecular para a ocorrência deste tipo de genes quiméricos está relacionada ao fato de que os loci cromossômicos participantes do rearranjo RET/PTC (por exemplo, RET e H4) estão justapostos durante a interfase em tecido humano tiroideano normal, oferecendo, desta forma, um alvo para a radiação induzir quebras no DNA que causariam uma recombinação não-homóloga das partes. Assim, a arquitetura cromossômica durante a interfase pode ser um pré-requisito importante para a recombinação do RET nas células tiroideanas; a despeito da distância linear (30 megabases no caso de H4 e RET), a contigüidade física dos genes envolvidos durante a interfase aumenta a chance de recombinação ilegítima após exposição a agentes genotóxicos $(3,19)$.

\section{Rearranjos RET/PTC em carcinomas de células de Hurthle}

Os tumores derivados das células oxifílicas ou de Hurthle são considerados variantes dos carcinomas foliculares de tiróide. Recentemente, porém, tem se modificado essa idéia, pois se verificou que um grupo de tumores de células de Hurthle tem características histológicas de carcinomas papilíferos, além de apresentar rearranjos do tipo RET/PTC e imuno-histoquímica positiva para RET (20). Esta re-classificação dos tumores de células de Hurthle ainda não é universalmente aceita, mas pode ter implicações práticas importantes, uma vez que o carcinoma papilífero de células de Hurthle pode ter um comportamento biológico distinto, pois apresenta metástases nos linfonodos regionais em oposição aos carcinomas de Hurthle sem rearranjos RET/PTC, que enviam metástases à distância $(2,20)$.

\section{Multicentricidade do carcinoma papilífero}

Os carcinomas papilíferos da tiróide são, habitualmente, multicêntricos por ocasião da apresentação inicial, não se sabendo se esses focos múltiplos representam micrometástases provenientes da mesma lesão primária ou seriam decorrentes de tumores distintos. Recentemente um trabalho evidenciou que 17 de 21 
pacientes com carcinoma papilífero multifocal eram positivos para RET/PTC e, desses, 15 apresentavam tipos diversos de RET/PTC mRNA nos tumores individuais dos diferentes pacientes, indicando que tiveram, provavelmente, eventos iniciadores diferentes. Esse dado indicaria que a tiróide desses pacientes foi exposta a uma agressão genotóxica importante, que causou dano disseminado ao DNA. Corroborando esta hipótese, os cânceres papilíferos em crianças são, comumente, multicêntricos $(3,21)$.

\section{Fusão PAX-8-PPAR $\gamma 1$ no Carcinoma Folicular da Tiróide}

Já se sabe, há algum tempo, que o carcinoma folicular apresenta uma via oncogênica distinta do carcinoma papilífero. Entre essas evidências incluem-se a prevalência maior de mutações ativadoras dos genes RAS e a predisposição muito maior para o desenvolvimento de anomalias na replicação do DNA. Até recentemente, porém, não havia anomalias genéticas descritas no câncer folicular de tiróide. Kroll e cols. publicaram uma possível base molecular ao descrever a translocação cromossômica $\mathrm{t}(2: 3)(\mathrm{q} 13 ; \mathrm{p} 25)$ apenas em carcinomas foliculares (22). O ponto de quebra do cromossomo $2 \mathrm{ql} 3$ fica dentro da região codificadora do fator de transcrição tiroideano PAX-8 e o cromossomo 3p24 dentro da região codificadora do PPAR $\gamma 1$. Esse rearranjo foi encontrado em $5 / 8$ carcinomas foliculares, mas em nenhum dos adenomas foliculares. Estudos funcionais para evidenciar se esse rearranjo poderia ser responsável pela gênese do carcinoma folicular ainda não foram feitos.

\section{Mutações Promotoras de "Ganho de Função" no Receptor de TSH}

Para o receptor de TSH (TSH-R) o termo "ganho de função" pode significar ativação na ausência do ligante (constitutividade), causadora da "autonomia" do tecido tiroideano (doença de Plummer), o aumento da sensibilidade ao agonista, que diminui o valor sérico de TSH e a ampliação de sua especificidade, que ocasiona estimulação da glândula, pois o novo agonista não faz o feedback negativo.

Em termos da tumorigênese molecular tiroideana existe um tipo de "ganho de função" para o TSH-R, representado por diversas mutações somáticas, causadoras da doença de Plummer, que ativam o TSH-R de modo constitutivo, uma vez que este é efetor de ambas as ações do TSH, as estimulatórias para a produção de $\mathrm{T} 4$ e as mitogênicas para a proliferação do tecido tiroideano $(23,24)$.
O gene do TSH-R fica no cromossomo 14 e codifica uma glicoproteína pertencente à família dos receptores ligados à proteína $\mathrm{G}$, constituída por uma região C-terminal semelhante a uma "serpentina" (codificada apenas pelo exon 10) e uma longa região $\mathrm{N}$-terminal codificada por 9 exons. Este domínio $\mathrm{N}$ terminal é o responsável pela ligação com o TSH, enquanto que a "serpentina" é a responsável pela transdução do sinal à proteína $\mathrm{G}$ (figura 5 ).

A maior parte das mutações encontram-se na terceira alça citoplasmática ou no segmento adjacente transmembranoso do TSH-R, o que indica que nessa área localiza-se uma região mais "quente" para mutações, mas já se descreveram alterações em todo o TSH-R (figura 5, tabela 3 ). Os produtos constituídos pelos aminoácidos substituintes promovem, de maneira geral, um aumento da atividade constitutiva do receptor por meio do estímulo de cAMP, além de evidenciarem uma afinidade maior pelo TSH que o receptor selvagem. Diversos trabalhos não têm encontrado uma relação entre as posições das mutações e suas características funcionais e todas apresentam fenótipos semelhantes $(23,24)$. Desta forma, essas informações referentes à patogênese molecular do nódulo autônomo não têm se traduzido, por enquanto, em algum aspecto prático no manejo dessa doença.

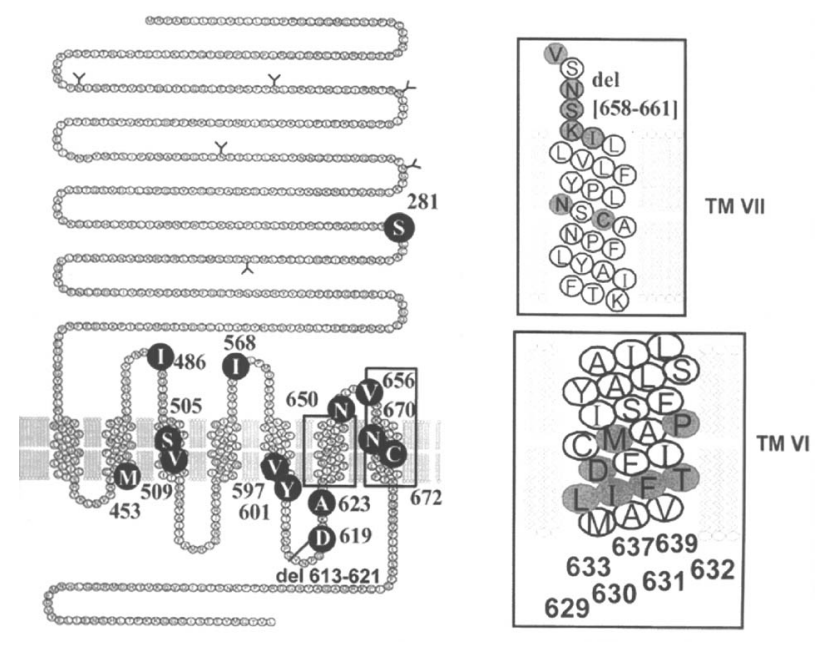

Figura 5. Esquema do receptor de TSH e suas mutações; a figura da esquerda mostra na porção superior o domínio Nterminal, extra-celular, ligante do TSH e na porção inferior o domínio C-terminal, ligado à proteína $G$, semelhante a uma "serpentina", que cruza a membrana 7 vezes. Os números indicam os códons das mutações já descritas no receptor de TSH. A figura da direita mostra as regiões transmembranosas $\mathrm{VI}$ e VII, onde ocorre o maior número de mutações (modificado a partir da referência 23). 
Tabela 3. Mutações ativadoras mais comuns do receptor de TSH

\begin{tabular}{|c|c|c|c|c|c|c|}
\hline CODON & Substituição & $\begin{array}{l}\text { Mutação } \\
\text { Somática }\end{array}$ & $\begin{array}{c}\text { Mutação } \\
\text { Germinativa } \\
\text { Nova }\end{array}$ & $\begin{array}{l}\text { Mutação } \\
\text { Germinativa } \\
\text { Familiar }\end{array}$ & $\begin{array}{c}\text { Estimulação } \\
\text { de } \\
\text { (cAMP) }\end{array}$ & $\begin{array}{c}\text { Estimulação } \\
\text { de } \\
\text { (IP) }\end{array}$ \\
\hline \multirow[t]{3}{*}{ Ser281 } & Asn & + & & & + & - \\
\hline & Thr & + & + & & + & - \\
\hline & lle & + & & & + & - \\
\hline Met453 & Thr & + & + & & + & - \\
\hline \multirow{2}{*}{ Ile 486} & Phe & + & & & + & + \\
\hline & Met & + & & & + & $+/-$ \\
\hline \multirow[t]{2}{*}{ Ser505 } & Arg & & & + & + & - \\
\hline & Asn & & + & & + & - \\
\hline Val509 & Ala & & & + & + & - \\
\hline Ile568 & Thr & + & & & + & $+/-$ \\
\hline Del613-631 & & + & & & + & - \\
\hline Asp619 & Gly & + & & & + & - \\
\hline \multirow[t]{3}{*}{ Ala623 } & lle & + & & & + & $+/-$ \\
\hline & Val & + & & & + & - \\
\hline & Ser & + & & & + & - \\
\hline Leu629 & Phe & + & & + & + & - \\
\hline Ile630 & Leu & + & & & + & - \\
\hline \multirow[t]{2}{*}{ Phe631 } & Leu & + & + & & + & - \\
\hline & Cys & + & & & & \\
\hline \multirow[t]{2}{*}{ The632 } & lle & + & + & & + & - \\
\hline & Ala & + & & & & \\
\hline \multirow[t]{4}{*}{ Asp633 } & Tyr & + & & & + & - \\
\hline & Glu & + & & & + & - \\
\hline & His & + & & & + & - \\
\hline & Ala & + & & & + & - \\
\hline Pro639 & Ser & + & & + & + & + \\
\hline Asn650 & Tyr & & & + & + & - \\
\hline Val656 & Phe & + & & & + & - \\
\hline Del658-661 & & + & & & + & - \\
\hline Asn670 & Ser & & & + & + & - \\
\hline Cys672 & Tyr & & & + & + & - \\
\hline
\end{tabular}

\section{Marcadores Moleculares no Diagnóstico e Seguimento do Câncer da Tiróide}

A literatura vem procurando, há algum tempo, marcadores que possam ser utilizados no diagnóstico molecular de diversas doenças da tiróide. O foco principal tem sido a busca do diagnóstico diferencial dos nódulos, tendo em vista a facilidade da obtenção de material por meio da punção aspirativa por agulha fina e algumas dificuldades trazidas pela citologia de tiróide, das quais destaca-se o diagnóstico de "lesão celular folicular" ou "proliferação folicular", que não distingue o carcinoma folicular de lesões benignas, como bócio colóide e o adenoma folicular. Assim, marcadores moleculares que pudessem discriminar essas lesões seriam muito úteis e tem-se tentado o emprego de vários, por meio da extração do RNA extraído do material de agulha e posterior RT-PCR de diversos genes. Os resultados, entretanto, ainda estão na fase pré-clínica.

Por outro lado, vários grupos têm proposto o uso do mRNA da tiroglobulina ( $\mathrm{Tg})$, detectado a partir de células tiroideanas circulantes, com o objetivo de utilizá-la especialmente naqueles casos onde a dosa- gem de tiroglobulina estiver prejudicada pela presença de anticorpos anti-tiroglobulina (25-27).

\section{AGRADECIMENTOS}

O autor agradece as discussões com Janete M. Cerutti, Rosa Paula M. Biscolla e Adriana M. Álvares da Silva, que foram muito úteis na preparação desta revisão.

\section{REFERÊNCIAS}

1. Barril N, Tajara EH. Aspectos moleculares do câncer tiroideano. Arq Bras Endocrinol Metab 1999;43:313-24.

2. Santoro M, Melillo RM, Carlomagno F, Fusco A, Vecchio $G$. Molecular mechanisms of RET activation in human cancer. Ann NY Acad Sci 2002;963:116-21.

3. Fagin JA. Perspective: Lessons learned from molecular genetic studies of thyroid cancer-insights into pathogenesis and tumor-specific therapeutic targets. Endocrinology 2002; 143:2025-8.

4. Ponder BAJ. Multiple Endocrine Neoplasia Type 2. In: Scriver CR, Beaudet AL, Valle D, Sly WS, editors. The 
metabolic and molecular bases of inherited diseases. $8^{\text {th }}$ ed., on line. McGraw-Hill:New York, 2002, section 5, chapter 42 (http//genetics.accessmedicine.com).

5. Hoff AO, Cote GJ, Gagel RF. Multiple endocrine neoplasias. Ann Rev Physiol 2000;62:377-41 1.

6 Maciel RMB. Diagnóstico e tratamento do câncer de tiróide. In: Vilar L, ed. Endocrinologia Clínica. 2a. Edição Medsi:Rio de Janeiro. 2001;207-18.

7. Maciel RMB. Câncer da tiróide. In: Wajchenberg BL, ed. Tratado de Endocrinologia. Roca: São Paulo. 1992 pp.404-27.

8. Brandi ML, Gagel RF, Angeli A, Bilezikian JP, Beck-Pec$\operatorname{coz} \mathrm{P}$, Bordi $\mathrm{C}$, et al. Guidelines for diagnosis and therapy of MEN type 1 and type 2. J Clin Endocrinol Metab 2001;86:5658-71.

9. Machens A, Gimm O, Hinze R, Hoppner W, Boehm BO, Dralle H. Genotype-phenotype correlations in hereditary medullary thyroid carcinoma: oncological features and biochemical properties. J Clin Endocrinol Metab $2001 ; 86: 1104-9$

10. Takahashi M, Ritz J, Cooper GM. Activation of a novel human transforming gene, ret, by DNA rearrangement. Cell 1985;42:581-8.

11. Punales MK. Rastreamento genético do carcinoma medular de tiróide: identificação de mutações no proto-oncogene RET. Tese de Mestrado. Faculdade de Medicina da Universidade Federal do Rio Grande do Sul, 2000, 67 pgs.

12. Nunes AB. Identificação de mutações do proto-oncogene RET associadas à forma hereditária do carcinoma medular de tiróide. Tese de Doutorado. Faculdade de Medicina da Universidade de São Paulo, 2002, 142 pgs.

13. Magalhães PKR. Estudo genético e imuno-histoquímico em carcinoma medular de tiróide. Tese de Doutorado. Faculdade de Medicina de Ribeirão Preto, Universidade de São Paulo, 2002, 125 pgs.

14. Álvares da Silva AM, Maciel RMB, Carvalho MB, Dias da Silva MR, Cerutti JM. Identificação de uma nova mutação no domínio extracelular do oncogene RET (G1557T) em uma família com carcinoma medular da tiróide. Arq Bras Endocrinol Metab 2002;46/1:S83.

15. Ribeiro RS, Álvares da Silva AM, Biscolla RPM, Dias da Silva MR, Chiamolera Ml, Macedo CRD, et al. Carcinoma medular de tiróide associado a NEM2B. Relato de um caso. Arq Bras Endocrinol Metab 2002;46/1:S136.

16. Puxeddu E, Fagin JA. Genetic markers in thyroid neoplasia. Endocrinol Metab Clin N Am 2001;30:493-513.

17. Bachelot A, Lombardo F, Baudin E, Bidart JM, Schlumberger $M$. Inheritable forms of medullary thyroid carcinoma. Biochimie 2002;84:61-6.

18. Bongarzone I, Fugazzola L, Vigneri P, Mariani L, Mondellini $P$, Pacini $F$, et al. Age-related activation of the tyrosine kinase receptor protooncogene RET and NTRK1 in papillary thyroid carcinoma. J Clin Endocrinol Metab 1996;81:2006-9.
19. Cerutti JA, Maciel RMB. Prevalência dos rearranjos RET/PTC em São Paulo. (em preparação).

20. Nikiforova MN, Stringer JR, Blough $R$, Medvedovic $M$, Fagin JA, Nikiforov YE. Proximity of chromosomal loci that participate in radiation-induced rearrangements in human cells. Science 2000;290: 138-41.

21. Cheung CC, Ezzat S, Ramyar L, Freeman JL, Asa SL. Molecular basis of Hurthle cell papillary thyroid carcinoma. $\mathrm{J}$ Clin Endocrinol Metab 2000;85:878-82.

22. Sugg SL, Ezzat S, Rosen IB, Freeman JL, Asa SL. Distinct multiple RET/PTC gene rearrangements in multifocal papillary thyroid carcinoma. J Clin Endocrinol Metab 1998:83:4116-22.

23. Kroll TG, Sarraf $P$, Pacciarini L, Chen C-J, Mueller E, Spiegelman BM, et al. PAX-8-PPARgl fusion oncogen in human thyroid carcinoma. Science 2000;289:1357-60.

24. Refetoff S, Dumont JE, Vassart G. Thyroid Disorders. In: Scriver CR, Beaudet AL, Valle D, Sly WS, editors. The metabolic and molecular bases of inherited diseases. $8^{\text {th }}$ ed., on line. McGraw-Hill:New York. 2002, section 8, chapter 158 (http//genetics.accessmedicine.com).

25. Corvilain B, Van Sande J, Dumont JE, Vassart G. Somatic and germline mutations of the TSH receptor and thyroid diseases. Clin Endocrinol 2001;55:143-58.

26. Ringel MD, Balducci-Silano PL, Anderson JS, Spencer $\mathrm{CA}$, Silverman J, Sparling YH, et al. Quantitative reverse transcription-polymerase chain reaction of circulating thyroglobulin messenger ribonucleic acid for monitoring patients with thyroid carcinoma. J Clin Endocrinol Metab 1999:84:4037-42.

27. Biscolla RPM, Cerutti JA, Maciel RMB. Detection of recurrent thyroid cancer by sensitive nested reverse transcription-polymerase chain reaction of thyroglobulin and sodium/iodide symporter messenger RNA transcripts in peripheral blood. J Clin Endocrinol Metab 2000;85:3623-7.

28. Fugazzola $L$, Mihalich A, Persani L, Cerutti N, Reina $M$, Bonomi $\mathrm{M}$, et al. Highly sensitive serum thyroglobulin and circulating thyroglobulin mRNA evaluations in the management of patients with differentiated thyroid cancer in apparent remission. J Clin Endocrinol Metab 2002;87:3201-8.

\section{Endereço para correspondência:}

Rui M.B. Maciel

Laboratório de Endocrinologia Molecular

Disciplina de Endocrinologia, Departamento de Medicina Universidade Federal de São Paulo

Centro de Pesquisas Oswaldo L. Ramos

Rua Pedro de Toledo 781 - $12^{\circ}$ Andar

04029-034 São Paulo, SP

fax: (011) 5084-5231

e.mail: rmbmaciel-endo@pesquisa.epm.br 